\title{
Validation of Molecular Markers for the Analysis of Genetic Diversity of Amylase Content and Gel Consistency among Representative Rice Varieties in Sri Lanka
}

\author{
H.K.D.H. Fernando, T.J.C. Kajenthini ${ }^{1}$, S.P. Rebeira ${ }^{2}$, \\ T.C. Bamunuarachchige ${ }^{3}$ and H.A.M. Wickramasinghe ${ }^{1}$ \\ Postgraduate Institute of Agriculture \\ University of Peradeniya \\ Peradeniya
}

\begin{abstract}
Starch is the major storage compound in almost all cereals including rice (Oryza sativa L.) and is used as a primary source of energy for humans. Furthermore, it is the main determinant of the eating and cooking quality (ECQ) of rice as amylose content $(A C)$ and gel consistency $(G C)$ are two parameters that significantly contribute to the ECQ. These parameters are mainly controlled by a major gene designated as Waxy or Wx, other minor genes such as ADP-glucose pyrophosphorylase isomerase (AGPiso) and environmental factors. The Waxy gene that encodes for the granule bound starch synthase (GBSS) enzyme which synthesizes amylase (meaning is not clear). The AGPiso (AGPase) gene, codes the protein glucose-1-phosphate adenylytransferase which plays a role in starch synthesis by catalyzing the synthesizing of activated glycosyl donor, ADP-glucose. In this study, an attempt was taken to demonstrate the correlation of AC and GC to three simple

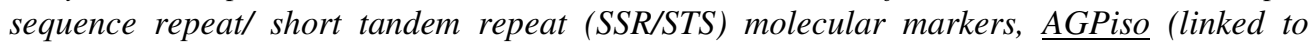

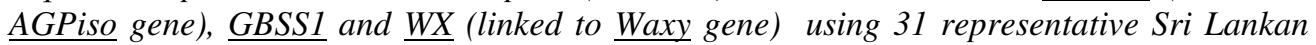
rice varieties. Among the tested rice varieties, the AC and GC varied from 14.8 to $27.7 \%$; and 3.4 to $9.0 \mathrm{~cm}$, respectively. All three markers gave multiple alleles (2-5 alleles), however, these markers did not show a significant association to the AC and GC of the tested rice varieties. Further analysis of the genetic variation of Suduru Samba and Kalu Heenati will be useful as they clustered separately from the rest of the tested varieties based on the polymorphism for markers $\underline{\text { AGPiso, }} \underline{\text { GBSSI }}$ and $\underline{\text { WX. }}$.
\end{abstract}

Keywords: Amylose content, gel consistency, molecular markers, rice eating and cooking quality

\section{INTRODUCTION}

Rice (Oryza sativa L.) is one of the most important and widely consumed food crops in the world. The rapid digestion of rice starch than any other high starchy food makes it distinctive among other cereals (Kent, 1982). Rice supplies nutrition for more than half of the world's population and it accounts for $21 \%$ of energy, $14 \%$ of protein and $21 \%$ of fat intake (Kennedy and Burlingam, 2003). The genus Oryza comprises of 25 species with only two cultivated species: $O$. sativa L. and $O$. glaberrima Steud. (Grist, 1986). There are three sub-

\footnotetext{
Department of Agricultural Biology, Faculty of Agriculture, University of Peradeniya, Sri Lanka

Department of Grain Quality, Rice Research and Development Institute, Bathalegoda, Sri Lanka

Department of Biological Sciences, Faculty of Applied Science, Rajarata University of Sri Lanka

* Corresponding author: mangalikaw@pdn.ac.lk
} 
species of $O$. sativa in Asia; indicia, japonica and javanica and cultivated varieties in Sri Lanka are of the indica sub-species. Based on the production statistics of World Food and Agriculture Organization, Sri Lanka is ranked $18^{\text {th }}$ among the rice producing countries in 2012 (FAO, 2013). There are more than 100 varieties currently cultivated in Sri Lanka, including both traditional and elite varieties (Jayawardena et al., 2010) grown in two seasons per year: Maha and Yala (Department of Census and statistics, 2012).

The grain quality of rice is conditioned by its physiochemical properties which are influenced greatly by genotype and environmental factors such as location, cultural practices and post harvest management (Hsieh et al., 1982). Rice quality basically depends on the satisfaction of the consumers. In general, the grain quality is derived into four categories; physical quality, milling quality, eating and cooking quality (ECQ) and nutritional quality.

ECQ is one of the key aspects that influence consumer's acceptability and their buying decisions. Consumers tend to buy quality rice despite the price (Cramer et al., 1993). ECQ is generally measured by tenderness, cohesiveness and glossiness of boiled rice and is controlled by both intrinsic and extrinsic parameters. There are mainly three intrinsic grain quality parameters that influence the ECQ of rice. They are amylase content (AC), gel consistency (GC) and gelatinization temperature (GT) (Khush et al., 1979). However, it is generally accepted that AC is the key determinant of the ECQ of rice (Juliano, 1971). Amylase content is directly correlated to volume expansion and water absorption during cooking (Cheng et al., 2012) and negetively correlated to cohessiveness, tenderness, colour and glossiness of boiled rice (Cruz and Khush, 2000). It is also a determinant of the market value (Larkin et al., 2003) and an indicator for classsifying rice varieties (Juliano, 1985). Amylose content influences texture and retrogradation potential of cooked grains (Champagne et al., 2004). In addition to AC, rice texture is also depends on structure and characteristic of amylopectin (Takeda and Hizukuri, 1987).

Gel consistency is a measure of firmness of cooked rice. It is used to classify rice varieties by measuring the length of a cooled gel made from flour previously cooked in $0.2 \mathrm{M} \mathrm{KOH}$ (Cagampange et al., 1973). Gel consistency used in rice improvement programs focusing on rice varieties with intermediate and lower AC classes. Rate of hardnening and hardness differences in cooked rice correlate with GC (Rohilla et al., 2000). If the GC is hard, then the cooked rice tends to be less sticky and if the GC is soft, then the cooked rice is more tender (Juliano, 1985). Gelatinization temperature is used in varietal development as an indicator of the cooking time (Cuevas et al., 2010). It is an economically important indicator of quality, because selecting for varieties with shorter cooking time can lead to savings in fuel costs (Fitzgerald et al., 2009).

Over the past several decades, various methods have been reported for the determination of ECQ parameters using phenotypic markers. Some of the limitations associated with phenotypic markers are the need for large quantity of sample for analysis, time and labour consuming analysis and high experimental errors involved (Takeda et al., 1986). Molecular markers are the most promising alternative to overcome these limitations and to evaluate the eating quality accurately for selections in rice breeding programs (Boulaphanh et al., 2011).

It is well documented that starch plays a key role in determining ECQ of rice (Kumar and Khush, 1987; Lee et al., 2007; Tian et al., 2009; Sun et al., 2011). Starch in rice endosperm contains two types of polysaccharides: amylose and amylopectin. Amylose accounts to approximately $0-30 \%$ of total starch in the endosperm and amylopectin to approximately 70-100\% (Martin and Smith, 1997). The ratio of these two polysaccharides is heritable and 
varies from cultivar to cultivar (Cai et al., 1998). Four groups of enzymes, such as ADPglucose pyrophosphorylase (AGP), starch synthase (SS), starch branching enzyme (SBE) and debranching enzyme (DBE) (James et al., 2003; Hannah and James, 2008) play a distinct role in starch biosynthesis (Ball, 1996; Myers et al., 2000), but presumbly function as a part of a network (Sun et al., 2011). Some with various isoforms lead to a specific starch end product (Pandey et al., 2012).

ADP glucose pyrophosphylase catalyzes the first reaction in starch synthesis, producing the activated glucosyl donor ADP-glucose (ADPG). AGPiso (AGP large subunit isoform) codes for the protien glucose-1-phosphate adenylyltransferase which is composed of 518 amino acids. Previous research revealed that AGPiso gene is responsible for GC of japonica rice (Sun et al., 2011) and acts as a minor gene affecting GC in all rice cultivars (Tian et al., 2009). AGPiso is a PCR based SSR marker linked to the AGPiso gene and the expected product size is approximately $98 \mathrm{bp}$ (Hsu et al., 2014).

Starch synthases (SS) utilize ADPG to elongate linear chains (James et al., 2003). A granulebound isoform, GBSSI, which is encoded by the Waxy (Wx) locus in cereals, functions specifically to elongate amylose (Shure et al., 1983). A major quantitative trait loci (QTL) contributing largely to the ECQ has been mapped to chromosome 6 corresponding to the Waxy locus. It encodes GBSS1, a key gene determining the percentage of amylose and ratio between amylose to amylopectin, the two critical factors affecting the ECQ. Six alleles of $W x$ have been found in natural germplasm (Hsu et al., 2014). GBSS1 marker is a SSR type PCR based marker derived from OSR19 to RM587 of QTL region (Kwon et al., 2008). The expected PCR product is 170 bp in size. The WX marker is a STS type PCR based marker with an expected band size of $100 \mathrm{bp}$ (Han et al., 2004). There are two classes of brancing enzymes (BE);BEI and BEII; that differ in terms of the length of the chains they transfer (Guan and Preiss, 1993). The amylopecten structures (Umemoto et al., 2002) and the percentage amylose content (Takeda et al., 1986) vary between japonica and indica rice.

Previous studies (Sun et al., 2011) have been carried out to show the genetic basis of ECQ with respect to DNA markers (13 markers including GBSS1 and AGPiso) and some of these markers were found to be useful in marker-assisted selection (MAS) of japonica rice (Hsu et al., 2014). However, no previous research has been carried out test them on indica background and therefore, the present study was carried out to validate the three molecular markers (AGPiso, GBSS1 and WX) in analyzing the genetic diversity of AC and GC in selected rice varieties representing the Sri Lankan rice germplasm, aiming to evaluate the usefulness of these molecular markers MAS in rice breeding programs.

\section{METHODOLOGY}

\section{Plant materials and preparation of seedlings}

Thirty one varieties of $O$. sativa (Table 3) were selected to represent the Sri Lankan rice germplasm. Rice seeds were obtained from an ongoing research at the Rice Research and Development Institute (RRDI), Bathalagoda and the seedlings were maintained at plant house of the Department of Agricultural Biology, Faculty of Agriculture, University of Peradeniya for DNA extraction. The japonica rice variety Nipponbare was used as the reference variety. A total of 10 seeds from each variety were germinated and seedlings were planted separately in labelled pots and maintained in the plant house. After three weeks, the leaves were harvested from each variety for DNA extraction. 


\section{Genomic DNA extraction and quantification}

Genomic DNA was extracted from three weeks old immature tender leaves using a modified CTAB method described by Murray and Thompson (1980). The extracted DNA was stored at $-20{ }^{\circ} \mathrm{C}$. Confirmation and quantification of the extracted genomic DNA was performed using a spectrophotometric method and agarose gel electrophoresis.

\section{Polymerase chain reaction}

Polymerase chain reaction (PCR) amplification was performed using a PCR reaction mixture of $20 \mu \mathrm{l}$ containing 1 unit of Taq DNA, $200 \mu \mathrm{M}$ of dNTPs, $0.5 \mathrm{pM}$ each of forward and reverse primers (Table 1) and $100 \mathrm{ng}$ of template genomic DNA. The thermal cycling conditions given are as follows: an initial denaturation for $5 \mathrm{~min}$ at $94{ }^{\circ} \mathrm{C} ; 35$ cycles of $1 \mathrm{~min}$ at $94{ }^{\circ} \mathrm{C} ; 1 \mathrm{~min}$ at optimized annealing temperature of $57{ }^{\circ} \mathrm{C}$ (AGPiso) $/ 56{ }^{\circ} \mathrm{C}\left(\right.$ WX) $/ 58{ }^{\circ} \mathrm{C}$ (GBSS1); 2 min at $72{ }^{\circ} \mathrm{C}$; and final extension of $10 \mathrm{~min}$ at $72{ }^{\circ} \mathrm{C}$. The PCR was performed on a thermal cycler (Thermal cycler 2720, Applied Bio systems USA).

Table 1. Primer sequences of the molecular markers tested in analyzing genetic diversity of Waxy and AGPiso genes

\begin{tabular}{|c|c|c|c|c|c|}
\hline Gene & $\begin{array}{c}\text { Marker } \\
\text { name }\end{array}$ & $\begin{array}{l}\text { DNA sequence } \\
\left(5^{\prime} \text {, to 3') }\right.\end{array}$ & Reference & $\begin{array}{c}\text { Melting } \\
\text { temperature } \\
\left({ }^{\circ} \mathrm{C}\right)\end{array}$ & $\begin{array}{l}\text { Product } \\
\text { size (bp) }\end{array}$ \\
\hline \multirow[t]{2}{*}{ AGPiso } & AGPiso & $\begin{array}{l}\text { F-CAA TCG CTG CCA } \\
\text { TCG GTT G }\end{array}$ & Hsu et al., 2014 & 60 & $90-120$ \\
\hline & & $\begin{array}{l}\text { R- TTC CAC ATC } \\
\text { GTT AGG TAC ACG }\end{array}$ & & 54 & \\
\hline \multirow[t]{4}{*}{ Waxy } & GBSS1 & $\begin{array}{l}\text { F-CAA ATA GCC } \\
\text { ACC CAC ACC AC }\end{array}$ & $\begin{array}{l}\text { Kwon et al., } \\
2008\end{array}$ & 56 & $170-250$ \\
\hline & & $\begin{array}{l}\text { R-CTT GCA GAT GTT } \\
\text { CTT CCT GAT G }\end{array}$ & & 54 & \\
\hline & $W X$ & $\begin{array}{l}\text { F-CTC TCT CAC CAT } \\
\text { TCC TTC AG }\end{array}$ & Han et al., 2004 & 52 & $90-120$ \\
\hline & & $\begin{array}{l}\text { R-CAC AAG CAG } \\
\text { AGA AGT GAA GC }\end{array}$ & & 53 & \\
\hline
\end{tabular}

The PCR products were first visualized using $2 \%$ agarose gel. Two- $\mu 1$ of loading buffer (98\% formaldehyde, $10 \mathrm{mM}$ EDTA, $0.025 \%$ bromophenol blue, $0.025 \%$ xylene cyanol) was mixed with $5 \mu 1$ of PCR product and was loaded to the agarose gel. Gel electrophoresis was carried out using a Mupid-2Plus gel electrophoresis apparatus (Advance, Japan) at $50 \mathrm{~V}$ for 1 hr. After staining with ethidium bromide $(0.05 \mu \mathrm{l} / \mathrm{ml})$ it was visualized using the UV light documentation system (BIO RAD, USA).

Polyacrylamide gel electrophoresis (PAGE) was carried out to detect the polymorphism among the thirty two varieties using amplified PCR products on an $8 \%$ acrylamide gel. The 100-bp ladder or the PCR products $(1.5 \mu \mathrm{l})$ were mixed with $1.5 \mu \mathrm{l}$ of $2 \times$ loading dye $(98 \%$ formaldehyde, $10 \mathrm{mM}$ EDTA, $0.025 \%$ bromophenolblue, $0.025 \%$ xylene cyanol) and was loaded to the gel. PAGE was done at $20 \mathrm{~mA} / \mathrm{gel}$ for $1.5 \mathrm{hr}$ using a vertical gel electrophoresis 
apparatus (Atto, Japan) and the gel was visualized using silver staining method described by Chevallet et al. (2006).

\section{Determination of amylase content and gel consistency}

Seeds from each variety cultivated in Maha (2012/2013) and Yala (2013) seasons at RRDI, Bathalagoda were harvested at maturity and shade dried to reduce the moisture content to 12-14\%. Seed samples of $150 \mathrm{~g}$ were dehulled using a Sakate dehusking machine (THU 358 ) and polished to a level of $\pm 8 \%$ of bran removal using a Satake dehusking machine (THO 5.0). Amylose content of each rice variety was estimated using the method described by Juliano (1971) and GC was determined by the method described by Cruz and Khush (2000) at the Grain Quality laboratory, RRDI, Bathalagoda.

\section{Data analysis}

The analysis of variance for data on AC and GC was performed using SAS 9.0 program and mean separation was performed using duncan multiple range test. Based on the marker polymorphism, a dendrogram was developed for 30 rice varieties (excluding two rice hybrids, $\mathrm{Bg} 407 \mathrm{H}$ and $\mathrm{Bg}$ 94-1) by performing a hierarchical cluster analysis (with 'complete linkage' clustering method and 'euclidean' distance measure) using the 'Rcmdr' package v2.0-4 in RStudio v0.98.978 (R Development Core Team, 2008).

\section{RESULTS AND DISCUSSION}

\section{Analysis of the genetic diversity at Wxay and AGPiso genes using molecular markers}

Five alleles were detected (designated as 1,2,3,4 and 5) for the marker AGPiso in the selected rice germplasm and twenty eight varieties out of the thirty two showed no polymorphism for the target SSR site in AGPiso gene. The varieties/hybrids that showed polymorphisms at the locus are Kalu Heenati (allele 2), Suduru Samba (allele 3), Bg 94-1(alleles 1 and 4) and Nippon bare (allele 5). Among tested varieties, three alleles (designated as 1, 2 and 3) were detected for markers WX and GBSS1. For those two markers, Kalu Heenati and Suduru Samba (both carrying the allele 2) showed polymorphism from all other Sri Lankan rice varieties (allele 1), while Nippon bare carried a different allele (allele 3) (Fig. 1 and Table 2). Therefore, two traditional rice varieties Kalu Heenati and Suduru Samba, and the reference variety Nippon bare showed polymorphism for all tested markers. For the marker AGPiso, Suduru Samba gave an amplified product which is slightly longer than 98 bp. Kalu Heenati amplified a longer product than Suduru Samba, which implies that it has a longer SSR sequence. Kalu Heenati and Suduru Samba (Fig. 1B, C) showed a different allele for both the target sites with slightly larger amplified product than all other varieties with approximate sizes of $200 \mathrm{bp}$ and $100 \mathrm{bp}$ for markers GBSS1 and WX, respectively.The japonica rice variety Nipponbare showed a different allele for all tested markers with a size in between 100 and 200 bp for marker AGPiso (Fig. 1A). 
Table 2. Allele types generated by each molecular marker for selected rice varieties

\begin{tabular}{llll}
\hline Rice Variety/ & \multicolumn{3}{c}{ Molecular marker } \\
\cline { 2 - 4 } Hybrid & AGPiso & WX & GBSS1 \\
\hline Kalu Heenati & 2 & 2 & 2 \\
Suduru Samba & 3 & 2 & 2 \\
Bg 94-1 & 1,4 & 1 & 1 \\
Bg 407H & 1 & 1,2 & 1,2 \\
Nippon Bare & 5 & 3 & 3 \\
\hline Total no of alleles & 5 & 3 & 3 \\
\hline
\end{tabular}
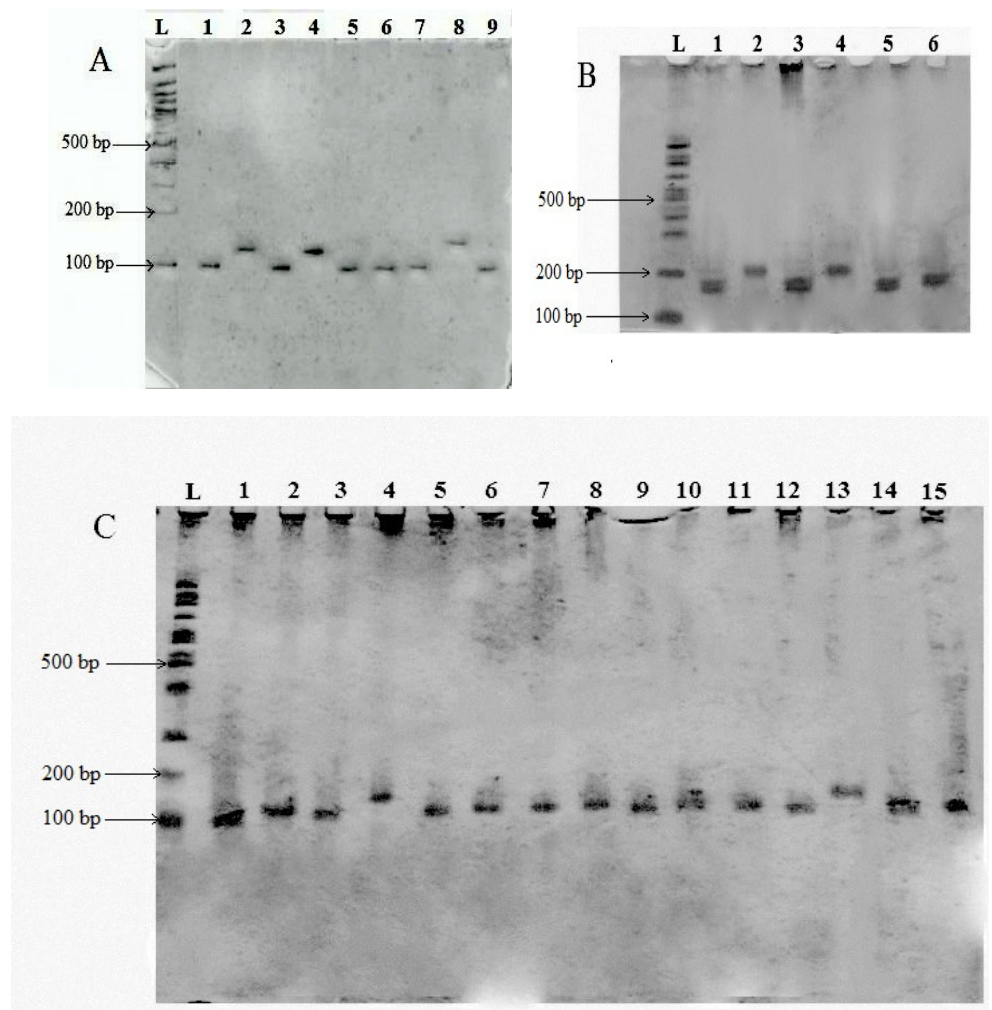

A: Polymorphism with marker AGPiso (L-100 bp ladder, 1-Bg 360, 2-Kalu Heenati, 3-Rathal, 4-Suduru Samba, 5At 306, 6-Bg 407-H, 7-Pachchaperumal, 8-Nipponbare, 9-Kahatawee) B: Polymorphism with markerGBSS1 (L- 100 bp Ladder, 1-Dular, 2-Suduru Samba, 3-Bg 58, 4-Kalu Heenati, 5-Masuran, 6-At 306) C: Polymorphism with marker WX (L-100 bp Ladder, 1-Wanni Dahanala, 2-Pachchaperumal, 3-Kahata wee, 4-Suduru Samba, 5Devaradiri, 6-Kuruluthuda, 7- Masuran, 8-Sudu Heenati, 9-Gonabaru, 10-Hondarawalu, 11-Sulai, 12-Madathawalu, 13-Kalu Heenati, 14-Maawee, 15-Inginimitiya)

Fig. 1. Polymorphism showed by the selected rice varieties for molecular marker AGPiso, GBSS1 and WX, on $8 \%$ polyacrylamide gels.

In the dendrogram resulted from the hiarachical cluster analysis, Kalu Heenati and Suduru Samba could be clustered separatly from the other 27 inbred varieties (Fig. 2). This indicates 
a close relationship among Sri Lankan rice for the tested markers. Suduru Samba and Kalu Heenati have shown different alleles with respect to all three markers tested. However, the marker vizualyzation technique used in the study was insufficient to clearly resolve the PCR products of the GBSS1 and $W x$ markers for above two varieties. Therefore, these two traditional rice vareities would be ideal for further studies in understanding their genetic background in relation to starch synthesis. The japonica reference variety Nipponbare clustered separately showing the clear genetic distance between japonica and indica type rice including genes responsible for starch sysntheis.

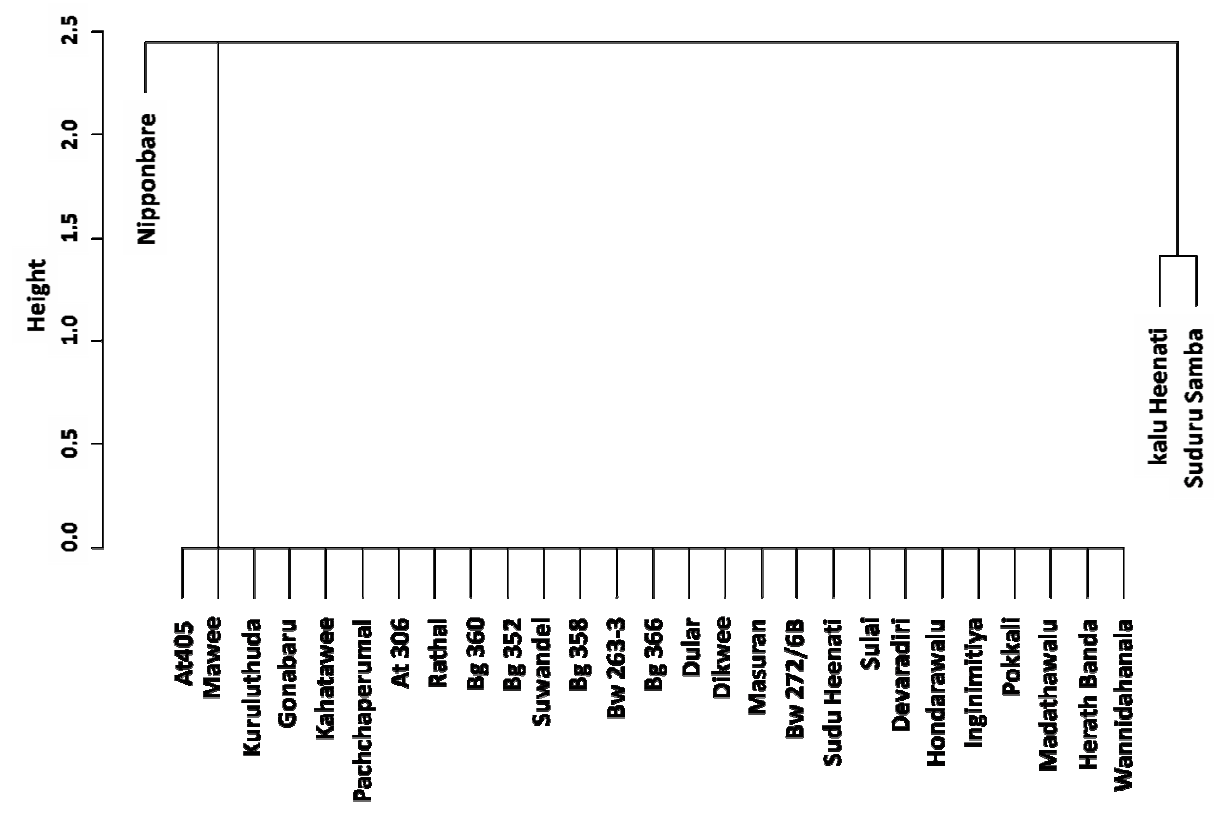

Fig. 2. Genetic relationship of Sri Lankan rice varieties based on molecular markers AGPiso, GBSS1, WX.

\section{Amylose content and gel consistency of selected rice varieties}

Amylose content of the evaluated varieties varied from the lowest of $14.8 \%$ (At 405) to the highest of $27.7 \%$ (Kahata Wee) with a majority (19 varieties out of 31) grouped in to the intermediate AC class (Table 3 ) according to the five amylose classes given by Kumar and Khush (1987) (high (>25\%); intermediate (20-25\%); low (10-19\%); very low (3-9 \%) and waxy (0-2\%)). Only At 405 could be catogorized under low AC group and there were 11 varieties that could be classified as high AC. The AC values determined by previous studies for some rice varieties showed relatively high for all the sampled varieties (Wickramasinghe and Noda, 2008; Rajapaksha et al., 2011). This could be due to differences in analysis procedures and influence of environmental factors. Amylose content is significantly affected by storage intervals, treatments (Khush et al., 1979) and method of measurement. A prevalent high ambient temperature during the ripening stage of the crop may increase the AC of cereals (Sun et al., 2011).

Traditional vareity Kuruluthuda has the highest GC value $(9.00 \mathrm{~cm})$ among the tested varieties, therefore, it may have the softest texture in cooked rice as research evidences 
proved that GC has a strong negative relationship to the texture of the cooked rice . $\mathrm{Bg} 360$ has the lowest GC with a value of $3.40 \mathrm{~cm}$. According to the classification; soft $(>6)$, medium (4-6) and hard (<4), Bg 360 is catogorized as having a "hard" texture. Nine varieites had low GC, but they all have a GC value very close to 4.0, therefore, eventhough they are catogorized under "hard" class, their texture falls barely in to the hard textured category when cooked. The majority of indica varieties have high AC, and low GC and GT values, while japonica varieties show low AC and high GC and a GT values (Tian et al., 2009). Varieties such as Herath Banda, Pokkali, Hondarawalu, Kuruluthuda, Sulai and At 405 are catogorized under soft GC class and are prefered over other varieties (Rohilla et al., 2000) by the consumers. Eleven varieties were classified to the medium GC class category.

Table 3. Variation of the average amylose content and the gel consistency of the tested rice varieties of Si Lanka

\begin{tabular}{|c|c|c|c|c|c|}
\hline Rice Variety & $\begin{array}{l}\text { Accession } \\
\text { No }\end{array}$ & Average AC (\%) & AC Class & $\mathrm{GC} / \mathrm{cm}$ & $\begin{array}{l}\text { GC } \\
\text { Class }\end{array}$ \\
\hline Herath Banda & 280 & 26.7 & High & 7.67 & Soft \\
\hline Kalu Heenati & 33 & 27.1 & High & 3.95 & Hard \\
\hline Wanni Dahanala & 591 & 24.2 & Intermediate & 5.83 & Medium \\
\hline Pachchaperumal & 799 & 23.5 & Intermediate & 3.70 & Hard \\
\hline Suwandel & 579 & 23.6 & Intermediate & 3.52 & Hard \\
\hline Madathawalu & - & 24.2 & Intermediate & 4.10 & Medium \\
\hline Pokkali & 809 & 23.3 & Intermediate & 7.30 & Soft \\
\hline Mawee & 87 & 23.2 & Intermediate & 4.52 & Medium \\
\hline Gonabaru & 28 & 21.9 & Intermediate & 3.50 & Hard \\
\hline Rathal & 133 & 21.7 & Intermediate & 3.65 & Hard \\
\hline Hondarawaalu & 285 & 25.6 & High & 7.15 & Soft \\
\hline Kahata Wee & 324 & 27.7 & High & 4.27 & Medium \\
\hline Kuruluthuda & 69 & 22.9 & Intermediate & 9.00 & Soft \\
\hline Devaradiri & 243 & 25.9 & High & 5.85 & Medium \\
\hline Suduru Samba & 903 & 20.6 & Intermediate & 3.61 & Hard \\
\hline Sulai & 502 & 25.2 & High & 6.42 & Soft \\
\hline Dik Wee & 246 & 24.4 & Intermediate & 3.75 & Hard \\
\hline Sudu Heenati & 491 & 23.8 & Intermediate & 3.75 & Hard \\
\hline Masuran & 86 & 23.1 & Intermediate & 3.65 & Hard \\
\hline Inginimitiya & - & 25.1 & High & 4.30 & Medium \\
\hline Dular & - & 22.4 & Intermediate & 5.30 & Medium \\
\hline At 405 & - & 14.7 & Low & 6.62 & Soft \\
\hline Bg 366 & - & 23.4 & Intermediate & 3.65 & Hard \\
\hline $\mathrm{Bg} 360$ & - & 22.9 & Intermediate & 3.40 & Hard \\
\hline At 306 & - & 24.4 & Intermediate & 4.27 & Medium \\
\hline $\mathrm{Bg} 407 \mathrm{H}$ & - & 25.2 & High & 3.80 & Hard \\
\hline Bg 358 & - & 26.9 & High & 3.60 & Hard \\
\hline Bg 352 & - & 27.6 & High & 4.70 & Medium \\
\hline Bg 94-1 & - & 25.8 & High & 3.97 & Hard \\
\hline Bw 267-3 & - & 22.2 & Intermediate & 4.35 & Medium \\
\hline Bw 272/6B & - & 26.1 & Intermediate & 5.45 & Medium \\
\hline
\end{tabular}




\section{Correlation analysis}

Eventhough the previous studies have reported a strong correlation between AC and GC (Cruz and Khush, 2000; Rohilla et al., 2000), in this study the correlation between AC and GC was not significant $\left(p=0.07 ; \mathrm{R}^{2}=0.11\right)$. Cruz and Khush, 2000 have also reported that differences in GC exists among varieties of similar amylose content. In cotrast, Singh et al. (2000) showed that AC have significant negative correlation with GC. Therefore, the correlation between AC and GC might depend on the varieties used and the diversity of the characters.

Furthermore it was not possible to detect an allelic association of any tested molecular marker with AC or GC, though some previous studies have shown such relationships with these markers to the ECQ in japonica rice (Sun et al., 2011; Hsu et al., 2014). The major reason for not detecting significant alleleic association in the current study could be due to the indica genetic background of the varieties tested. Therefore, more molecular markers should be examined and further linkage studies should be carried out with Sri Lankan rice varieties.

\section{CONCLUSION}

Amylose content of the evaluated varieties varied from 14.8 (At 405) to 27.7\% (Kahata Wee) and the GC variation was from $3.4 \mathrm{~cm}$ (Bg 360) to $9.0 \mathrm{~cm}$ (Kurulu thuda). No significant correlation was shown between the above two characters. The three molecular markers AGPsio, WX and GBSS1 gave multiple alleles, however, none of the markers clearly correlated to either AC or GC of the tested varieties. Therefore, they could not be used for MAS for the selected rice varieties. Since Suduru Samba and Kalu Heenati have different alleles in all three molecular marker target regions, they would appeared to have a deviated genetic background with respect to the target regions of both Waxy and AGPiso genes. Therefore these two traditional rice vareities would be ideal for further studies in understanding their genetic background in relation to starch synthesis.

\section{ACKNOWLEDGEMENT}

The authors are grateful Dr. H.M.V.G.Herath and Ms. D. V. Jayathilake for their assistance in data analysis and to Ms T.P. Jayaweera for the assistance given in the laboratory techniques. Financial assistance received by National Research Council (NRC 11-86) is greatly acknowledged.

\section{REFERENCES}

Ball, S.G. (1996). From glycogen to amylopectin: A model for the biosynthesis of the plant starch granule. Cell., 86, 349 - 352.

Boualaphanh, C., Daygon, V.D., Calingacion, M.N., Sanitchon, J., Jothityangkoon, D., Mumm, R., Hall, R.D. and Fitzgerald, M.A. (2011). Use of new generation single nucleotide polymorphism genotyping for rapid development of near-isogenic lines in rice. Crop Sci., 51, 2067 - 2073. 
Cagampange, G.B., Perez, C.M. and Juliano, B.O. (1973). A gel consistency test for eating quality in rice. Sci. Food and Agric., 24, 1589 - 1594.

Cai, X.L.,Wang, Z.Y. and Xing, Y.Y. (1998). Aberrant splicing of intron 1 leads to the heterogeneous 5'UTR and decreased expression of waxy gene in rice cultivars of intermediate amylose content. Plant J., 14(4), 459 - 465.

Champagne, E.T., Wood, D.F., Juliano, B.O. and Bechtel, D.B. (2004). The rice grain and its gross composition. Rice Chem. Tech., 3, 77 - 100.

Cheng, A., Ismail, I., Osman, M. and Hashim, H. (2012). Simple and rapid molecular techniques for identification of amylose levels in rice varieties. Int. J. Mol. Sci., 13, 61566166.

Chevallet, M., Luche, S. and Rabilloud, T. (2006). Silver staining of protiens in polyacrylamide gels. Nat. Protoc., 1, 1852 - 1858.

Cramer, G.L., Wailes, E.J. and Shui, S. (1993). Impact of liberizing trade in the world rice market. Am. J. Agric. Econ., 75(1), 219 - 226.

Cruz, N.D. and Khush, G.S. (2000). Rice grain quality evaluation procedures. pp 15-28. In: Sing, R.K., Sing, U.S. and Khush, G.S. (Ed). Aromatic rices. Oxford and IBH publishing Co (Pvt) Ltd. New Delhi, India.

Cuevas, R.P., Daygon, V.D., Corpuz, H.M., Reinke, R.F.,Waters, D.L.E. and Fitzgerald, M.A. (2010). Melting the secrets of geletinization temperature in rice. Func. Plant Biol., 37, $439-447$.

Department of Census and Statistics, Colombo, Sri Lanka, (2012).

FAO (2013). Major rice producing countries and global rice trade. [on line]. [Accessed on 12.05.2014]. Available at http:// www.FAO.org.

Fitzgerald, M.A., McCouch, S.R. and Hall, R.D. (2009). Not just a grain of rice: the quest for quality. Trends Plant Sci., 14(3), 133 - 139.

Grist, D.H. (1986). Characteristics of the plant. pp 69-98 in Rice, $6^{\text {th }}$ edition. Colonial Agriculture Service, Malaysia.

Guan. H. and Preiss, J. (1993). Differentiation of the properties of the branching isozymes from maize (Zea mays). Plant Physiol., 102, 1269 - 1273.

Han, Y., Xu, M., Liu, X., Yan, C., Korban, S.S., Chen, X. and Gu, M. (2004). Genes coding for starch branching enzymes are major contributors to starch viscosity characteristics in waxy rice (Oryza sativa L.). Plant Sci., 166, 357 - 364.

Hannah, L.C. and James, M. (2008). The complexities of starch biosynthesis in cereal endosperm. Curr. Opin. Biotechnol., 19, 160 - 165. 
Hirose, T. and Terao, T. (2004). A comprehensive analysis of the starch synthase gene family in rice (Oryza sativa L.). Planta., 220(1), 9 - 16.

Hsieh, S.C. and Kuo, Y.C. (1982). Evaluation and genetical studies on grain quality characters in rice. Proceeding of the Plant Breeding Symposium. By ROC Regional Society of SABRAO, 99-112.

Hsu, Y.C., Tseng, M.C., Wu, Y.P., Lin, M.Y., Wei, F.J., Hwu, K.K., Hsing, Y.I. and Lin, Y.R. (2014). Genetic factors responsible for eating and cooking qualities of rice grains in a recombinant inbred population of an inter-subspecific cross. Mol. Breeding, 10, 0065-8.

James, M.G., Denyer, K. and Myers, A.M. (2003). Starch synthesis in the cereal endosperm. Curr. Opinion Plant Biol., 6, 215-222.

Jayawardena, S.N., Muthunayake, M.M.P. and Abesekara, S.W. (2010). Present status of varietal spread of rice in Sri Lanka. Annals of Sri Lanka Depart. Agric., 12, 247-256.

Juliano, B.O. (1971). A simplified assay for milled rice amylose. Cereal Sci. Today, 16(10), $334-340$.

Juliano, B.O. (1985). Criteria and tests for rice grain qualities. Rice Chemistry and Technology, $2^{\text {nd }}$ edition, American Association of Cereal Chemists, St Paul, MN, 443-513.

Kennedy, G. and Burlingame, B. (2003). Analysis of food composition data on rice from a plant genetic resources perspective. Food Chem,. 80, 589 - 596.

Kent, N.L. (1982). Technology of cereals with special reference to wheat. Pergamon Press, New York.

Khush, G.S., Paule, C.M. and Cruz, N.M. (1979). Rice grain quality evaluation and improvement at IRRI. Proceeding of the Workshop on the Chemical Aspects of Rice Grain Quality. IRRI, Philippines, 21-31.

Kumar, I. and Khush, G.S. (1987). Genetic analysis of different amylose levels in rice. Crop Sci., 27(6), 1167 - 1172.

Kwon, S.J., Cho, Y.C., Kwon, S.W., Oh, C.S., Suh, J.P., Shin, Y.S., Kim, Y.G., Holligan, D., Wessler, S.R., Hwang, H.G. and Ahn, S.N. (2008). QTL mapping of agronomic traits using an RIL population derived from a cross between temperate japonica cultivars in rice (Oryza sativa L.). Breeding Sci., 58, 271 - 279.

Larkin, P.D., Mcglung, A.M., Ayers, N.M. and Park, W.D. (2003). The effect of the Waxy locus (granule bound starch synthase) on pasting curve characteristics in specialty rice (Oryza sativa L.). Euphytica., 134, 1 - 11.

Lee, S.K., Hwang, S.K., Han, M., Eom, J.S., Kang, H.G., Han, Y., Choi, S.B., Cho, M.H., Bhoo, S.H., An, G., Hahn, T.R., Okita, T.W. and Joen, J.S. (2007). Identification of the ADP-glucose pyrophosphorylase isoforms essential for starch synthesis in the leaf and seed endosperm of rice (Oryza sativa L.). Plant Mol. Biol., 65(4), 531 - 46. 
Martin, C. and Smith, A.M. (1997). Starch biosynthesis. Plant Cell., 7, 971 - 985.

Murray, M.G. and Thompson, W.F. (1980). Rapid isolation of high molecular weight plant DNA. Nucleic Acid Res., 8, 4321 - 4325.

Myers, A.M., Morell, M.K., James, M.G. and Ball, S.G. (2000). Recent progress toward understanding biosynthesis of amylopectin crystal. Plant Physiol, 122, 989 - 997.

Pandey, M.K., Rani,N.S., Madhav, M.S., Sundaram, R.M., Varaprasad, G.S., Sivaranjani, A.K., Bohra, A., Kumar, G.R. and Kumar, A. (2012). Different isoforms of starchsynthesizing enzymes controlling amylose and amylopectin content in rice (Oryza sativa L.). Biotechnol. Adv., 30, 1697 - 1706.

Rajapakshe, D., Benthota, A.P., Wijesundara, S.M., Premakumara, G.A.S. and Herath, T. (2011). Properties of some traditional rice varieties of Sri Lanka. Industrial Technology Institute and Department of Agriculture, Sri Lanka, p61.

R Development Core Team (2008). R: A language and environment for statistical computing. R Foundation for Statistical Computing, Vienna, Austria. URL http://www.Rproject.org.

Rohilla, R., Singh, V.P., Singh, U.S., Singh, R.K. and Khush, G.S. (2000). Crop husbandry and environmental factors affecting aroma and other quality traits. pp201-216. In: Singh, R.K., Singh,U.S. and Khush,G.S. (Ed). Aromatic rices. Oxford and IBH publishing Co (Pvt) Ltd. New Delhi, India.

Shure, M., Wessler, S. and Federoff, N. (1983). Molecular identification and isolation of the Waxy locus in maize. Cell, 35, $225-233$.

Sun, M.M., Abdulla, S.E., Lee, H.J., Cho, Y.C., Han, L.Z., Koh, H.J. and Cho, Y.G. (2011). Molecular aspect of good eating quality formation in japonica rice. Plos One. DOI:10.1371/journal.pone.0018385.

Singh, P.K., Gautam, P.L., Saxena, S. and Singh, S. (2000). Scented rice germplasm conservation, evaluation and utilization. pp 107-133. In Singh, R.K., Sinh, U.S. and Khush, G.S. (Ed) Aromatic rices. Oxford and IBH Publishing Co (Pvt) Ltd., New Delhi, India.

Takeda, Y., Hizukuri, S. and Juliano, B.O. (1986). Purification and structure of amylose from rice starch. Carbohyd. Res., 148, 299 - 308.

Takeda, Y. and Hizukuri, S. (1987). Structure of rice amylopectin with low and high affinities for iodine. Carbohydr. Res., 168, 79 - 88.

Tian, Z., Qian, Q.,Liu, Q.,Yan, M., Liu, X., Yan, C., Liu, G.,Gao, Z., Tang, S., Zeng, D., Wang, Y., Yu, J., Gu, M. and Li, J. (2009). Allelic diversities in rice starch biosynthesis lead to a diverse array of rice eating and cooking qualities. PNAS., 106(51), 21760 - 21765.

Umemoto, T., Yano, M., Satoh, H., Shomura, A. and Nakamura, Y. (2002). Mapping of a gene responsible for the difference in amylopectin structure between japonica-type and indica-type rice varieties. Theor. Appl. Genet., 104, 1 - 8.

Wickramasinghe, H.A.M. and Noda, T. (2008). Physiochemical properties of starches from Sri Lankan rice varieties. Food Sci. Technol. Res., 14(1), 49 - 54. 